\title{
DA INFLEXÃO PRÉ-CONSTITUCIONAL AO SUS MUNICIPALIZADO*
}

Monika Dowbor

\section{Introdução ${ }^{1}$}

A análise proposta neste artigo, que contempla a trajetória do setor público de saúde a partir dos anos 1970 a meados de 2000 pelo prisma de interação entre os principais atores societários e o Estado, sustenta dois argumentos. O primeiro deles, na contramão da interpretação vigente na literatura, defende que a inflexão no setor brasileiro de saúde, no

\footnotetext{
* A primeira versão deste trabalho foi apresentada no encontro da equipe desta pesquisa, em abril de 2006, e recebeu valiosas contribuições da professora doutora Amélia Cohn (Cedec) e Jorge Kayano (Instituto Polis). A elaboração da presente versão contou com a colaboração constante dos membros do projeto - Adrian Gurza Lavalle, Peter P. Houtzager, Fernanda Cernea, Fernanda Santos e Graziela Castello, a quem agradeço pelos numerosos comentários e reflexões coletivas que foram substanciais para a construção do argumento. A primeira seção deste artigo foi publicada em 2008, no IDS Bulletin, vol. 38, n. 6, sob o título "Origins of Successful Health Sector Reform: Public Health Professionals and Institutional Opportunities in Brazil".

${ }^{1}$ Este artigo faz parte das atividades previstas na pesquisa internacional intitulada "A reforma de serviços públicos: o papel da ação coletiva e da accountability social (Delhi, Cidade de México e São Paulo), coordenada pelos professores doutores Peter P. Houtzager, Adrian Gurza Lavalle, e Anuradha Joshi. Informações gerais sobre o projeto e sua metodologia podem ser encontradas em: http://www.ids. ac.uk/futurestate/research/Phase2/prog2/projects/modesofservdel.html
} 
sentido da universalização de acesso gratuito e integral por meio da descentralização, ocorreu no início dos anos 1980, ainda na vigência do regime militar, e deveu-se à intensa e particular interação entre os profissionais de saúde e o Estado. O segundo argumento refere-se ao período do Sistema Único de Saúde (SUS) e aponta que sua implementação ocorreu por meio da municipalização completa da atenção básica, fortemente marcada pela adoção de dois programas federais. Ao destacar os episódios de interação entre os principais atores dessa fase, o processo é interpretado como resultado de negociações entre o Ministério da Saúde e os secretários municipais de saúde.

Pautado na abordagem da polis, ${ }^{2}$ que privilegia a análise de processos pelo prisma de atores capazes de incidir na política, atentando para suas formas de atuação e interação, interesses e propostas, o primeiro argumento evidencia a intensidade de interação entre o movimento 186 sanitário atuante em prol das reformas e as instituições estatais durante o regime militar. A configuração propícia para as reformas no início da década de 1980 surgiu na medida em que, por um lado, havia profissionais de saúde agrupados no movimento sanitário que optaram majoritariamente pela prática reformista no interior das instituições estatais e, por outro, quando se instalou, em 1981, a aguda crise financeira do setor que permitiu questionamento do modelo em vigência. A conjunção desses fatores possibilitou a adoção de medidas de cunho reformista implementadas paulatinamente no país inteiro, a despeito dos interesses contrários do setor privado de medicina. As políticas adotadas conformaram mais do que um viés racionalizador ou apenas uma linha de ações programáticas de alcance limitado; constituíram quadro de uma

2 Para a apresentação dos principais eixos desta abordagem (polity-centred approach), ver Houtzager (2004). 
reforma original e contraditória em relação a sua época, que não privatizou nem estatizou o setor, mas, antes mesmo dos grandes consensos sobre as reformas de serviços públicos, iniciou a descentralização e a universalização de acesso integral a todos os serviços e manteve o prestador privado como fornecedor de serviços públicos.

Esta interpretação contrasta com a posição mais recorrente adotada pela literatura preocupada com as reformas no setor de saúde no Brasil, que produziu a narrativa sobre a trajetória pautada na necessária associação do projeto para o setor com a democratização da sociedade e do Estado e na consequente crítica ao regime autoritário instalado pelos militares entre 1964 a 1984. Assim, a Constituição de 1988, que selou com sua força e legitimidade o retorno à democracia, é considerada como ponto de inflexão setorial ao substituir com o Sistema Único de Saúde o modelo promovido pelo governo militar, que era excludente, centralizado, fragmentado institucionalmente, hospitalocêntrico tendo como principal fornecedor o setor privado da medicina.

O segundo argumento evidencia os termos da implementação do SUS como resultados de negociações entre o Ministério da Saúde (MS), órgão responsável pela coordenação e financiamento do sistema, e os municípios, promovidos ao status de entes federados e representados pelos secretários municipais de saúde. O MS conduziu a municipalização de serviços de saúde na sua totalidade no nível da atenção básica, fortemente marcado pela adoção de dois programas federais, o Programa de Agentes Comunitários de Saúde (Pacs) e o Programa Saúde da Família (PSF), que abrangiam com suas ações 100 milhões de pessoas em 2007. Os secretários municipais de saúde não foram passivos nesse processo: cresceram como ator capaz de incidir na política por meio de sua organização, o Conselho Nacional de Secretários Municipais de Saúde (Conasems), conduziram 
a 9. ${ }^{\text {a }}$ Conferência em 1992 realçando o vetor da municipalização, promoveram a instalação dos espaços de negociação intergovernamental participando das principais barganhas setoriais.

O artigo apresenta, na primeira seção, os principais atores que compuseram a cena do setor nos anos 1970, a saber, o regime militar junto com sua tecnoburocracia e setor privado de medicina e movimento sanitário. Com esta descrição como pano de fundo, a segunda seção focaliza o processo das reformas que introduziram a inflexão no setor no início dos anos 1980 . Na terceira seção apresenta-se a reconfiguração dos atores após a Constituição, com especial ênfase aos secretários municipais de saúde que desempenharam papel importante no estabelecimento dos termos da implementação do SUS. Estes termos serão discutidos na quarta seção. Na conclusão, são ressaltadas algumas das possíveis indicações sobre as reformas

188 de políticas públicas a partir desta releitura da experiência brasileira.

\section{A inflexão pré-constitucional no setor de saúde}

A análise desta seção diz respeito à trajetória do setor de saúde no plano nacional, na segunda metade dos anos 1970, focalizando a atuação e propostas de atores capazes de influir na elaboração da política setorial: o Estado junto com sua tecnoburocracia e com o setor privado de medicina e o movimento sanitário. A descrição revela que, diferentemente do que sustenta a literatura especializada, o modelo de saúde implementado pelo regime militar apresentou alguns avanços consideráveis e as instituições do setor foram abertas para os profissionais com visão reformista. O movimento sanitário conseguiu, paulatinamente, uma inserção nas instituições públicas, ganhando experiência e aglutinando seus componentes em torno de uma proposta única. 


\section{Governo militar, tecnoburocracia e medicina privada}

Os militares, que estiveram no poder no Brasil desde 1964 a 1984, instalaram um regime autoritário no qual a restrição dos direitos políticos pressupunha a manutenção de eleições, diretas para a maioria dos municípios e indiretas para o presidente, governadores e principais capitais, e a criação do sistema bipartidário. No campo dos direitos sociais, por sua vez, o regime se caracterizou pela sua expansão (Carvalho, 2007). Mais especificamente no setor de saúde, embora o acesso à saúde não tivesse se tornado um direito universal, houve implementação de uma série de medidas que ampliavam a cobertura, fomentavam programas de atenção básica e integravam os serviços públicos de saúde ao sistema federal. Esta interpretação contesta um dos consensos presentes na literatura do setor que tende a descrever o modelo de saúde promovido pelo regime militar em termos de exclusão, fragmentação institucional, centralização, indicando seu caráter hospitalocêntrico e a predominância do setor privado como fornecedor de assistência médico-hospitalar ao Estado (Noronha e Levcovitz, 1994; Barros, Piola, Vianna, 1996; Cohn, 2003; Saddi, 2004; Cohn e Elias, 2005).

Esta caracterização encontrada em boa parte da literatura preocupada com os avanços e retrocessos do Sistema Único de Saúde, produzida ao longo dos anos 1990, explicase pelo comprometimento de seus autores com o projeto da reforma de saúde indissociável do projeto da democratização da sociedade brasileira, expresso no famoso lema "Saúde e Democracia”. Avaliadas a partir deste ponto de vista, as mudanças e reformas realizadas pelo regime militar, que havia restringido as regras do jogo democrático e promovido uma forte opressão da oposição, não puderam passar de medidas administrativas e racionalizadoras.

Assim, onde a literatura lê a exclusão, isto é, a divisão da população entre os contribuintes da Previdência e, por isso, 
portadores do direito à assistência médico-hospitalar e os não contribuintes, pode-se entrever o progressivo processo de inclusão de categorias cobertas pelos serviços daquela assistência: em 1971, foram incorporados ao benefício de assistência médica os trabalhadores rurais; em 1972, os empregados domésticos; em 1973, os trabalhadores autônomos; em 1974, os maiores de 70 anos e inválidos e, em 1975, os empregadores rurais. Embora a expansão não seja ignorada na literatura, raramente é demonstrada em números, e estes indicam inegáveis avanços: entre 1968 e 1978, o número de segurados contribuintes praticamente triplicou: passou de 7.763.058 de contribuintes para 21.166.088 (Possas, 1980, p. 276) Se considerar o ano 1960 (antes do regime militar) quando se registravam 4.058.00 assegurados, o crescimento até 1975 quintuplicou. A expansão da cobertura pode ser também expressa pelo número total dos beneficiados, quando incluídos no contingente dos contri-

190 buintes da previdência os seus dependentes: em 1977, chega-se ao número de 55 milhões de pessoas de um total de 113.208.500 habitantes do país (Possas, 1980, p. 276). No final da década de 1970, a assistência médica da previdência social cobria $80 \%$ da população economicamente ativa (Bahia, 2005, pp. 427 e 431).

A fragmentação institucional sublinhada pela literatura refletia a divisão de responsabilidades pela provisão dos serviços de saúde agrupados em dois conjuntos distintos: os serviços de saúde coletiva (prevenção e cuidados de alcance coletivo), que eram da responsabilidade do Ministério da Saúde, ao lado das secretarias estaduais e municipais de saúde, e os serviços de assistência médico-hospitalar individual, vinculados ao Ministério de Previdência e Assistência Social (MPAS) ${ }^{3}$. No entanto, cabe frisar que essa divisão

\footnotetext{
${ }^{3}$ No Ministério da Previdência e Assistência Social havia quatro áreas nas quais eram alocados os recursos: administração, saúde, assistência e previdência. A partir de 1978, foram criadas novas agências, cada qual responsável por uma dessas áreas.
} 
institucional, sem dúvida problemática do ponto de vista de cuidados com a saúde, substituiu, em 1967, um sistema pulverizado de instituições responsáveis pelo benefício da assistência médica - os Institutos de Aposentadoria e Pensões ${ }^{4}$ - que congregavam trabalhadores por categoria profissional e eram independentes entre si. O regime militar conseguiu unificar os Institutos num único órgão, o Instituto Nacional de Previdência Social, e uniformizou os benefícios em 1977.

A assistência médico-hospitalar, que atendia os contribuintes da previdência social, foi desenvolvida tendo como fornecedor principal do Estado o setor privado da medicina, o que significou a continuidade da tendência anterior ao regime militar (Cohn, 2003, p. 44). Ao acompanhar os dados referentes ao número de leitos em séries históricas, pode-se observar que a proporção entre os públicos e os particulares, já em 1950, apontava para a predominância destes últimos: 46,1\% contra 59,9\% (Possas, 1980, p. 309). O regime militar expandiu em apenas $14 \%$ a presença de leitos privados, e a mudança mais considerável ocorreu por conta do aumento do segmento lucrativo da medicina, que chegou a ocupar mais espaço do que o tradicional fornecedor filantrópico.

A lógica do modelo era sustentável e lucrativa para as empresas privadas na medida em que o número de estabelecimentos hospitalares privados crescia na base de financiamentos públicos e baratos e o setor garantia para si, por meio da articulação com partes da burocracia, os contratos com a previdência. Se em 1960, apenas 14,4\% dos leitos privados eram lucrativos, em 1975, estes já atingiam 45,2\% (Possas, 1980, p. 309). No plano político-institucional, o crescimento do setor lucrativo da medicina refletia a articu-

\footnotetext{
${ }^{4}$ Os Institutos abrangiam as principais categorias profissionais urbanas do país, tais como marítimos, comerciários, bancários, industriários, trabalhadores em transporte e carga e trabalhadores de ferrovias e serviços públicos.
} 
lação entre os segmentos da burocracia previdenciária e os representantes dos interesses do complexo médico-industrial (Cordeiro, 1991, p. 33) entre os quais estavam a Federação Brasileira de Hospitais (FBH), a Associação Brasileira de Hospitais (ABH), a Federação Nacional de Estabelecimentos e Serviços de Saúde (Fenaess), os sindicatos estaduais de hospitais, a representação das Medicinas de Grupo (Associação Brasileira de Medicina de Grupo - Abramge) e a Associação Médica Brasileira (AMB), ao lado dos representantes menos evidentes da indústria farmacêutica, de equipamento médico-hospitalar, odontológico e de outros insumos.

A concentração da avassaladora parte de recursos de saúde no MPAS - em torno de $85 \%$ - responsável pela promoção da atenção médico-hospitalar, serviu de argumento para denominar o modelo como hospitalocêntrico, isto é, aquele que promove as ações curativas em detrimento das 192 preventivas e tem no hospital o principal equipamento de atendimento. Esta ênfase produz o eclipse das ações empreendidas pelo Ministério de Saúde, no qual se enraizaram interesses alternativos. Justamente a magra fatia de recursos deixou este Ministério numa posição marginal e, por isso, mais aberta às tendências da medicina comunitária e abordagem racionalizadora, sintonizadas com a abordagem das organizações internacionais de saúde e alternativas à ênfase dada à assistência médico-hospitalar. Médicos sanitaristas, que ocuparam cargos de direção no Ministério, compunham, com relativa liberdade, suas equipes e empreendiam programas de extensão de cobertura, principalmente nas áreas rurais. Esta atuação foi possibilitada pelo II Plano Nacional de Desenvolvimento de 1975 que colocou a problemática social no seu centro e desencadeou altos investimentos. A título de ilustração, vale lembrar que o orçamento do MS, em 1975, teve um aumento de 35,7\% em relação ao ano anterior (Almeida e Oliveira, 1979, p. 5, apud Esco- 
rel, 1998, p. 58). Um outro espaço institucional ocupado por essa vertente foram a V e a VI Conferências Nacionais de Saúde - espaços de discussão técnica e governamental, realizadas em 1975 e 1977, respectivamente -, nas quais a atenção médico-sanitarista era a principal pauta (Escorel, 1998). É importante notar que em 1974, com a eleição do presidente Geisel, um médico com visão reformista, Paulo de Almeida Machado, assumiu a pasta do Ministério de Saúde e compôs sua equipe pelos médicos que participaram do processo de reformas em São Paulo como José Carlos Seixas, João Yunes, Edmundo Juarez, José da Rocha Carvalheiro (Rodrigues Neto, 1997, p. 65).

Em resumo, pode-se afirmar que o regime militar promoveu, no setor de saúde, a ampliação considerável da cobertura de assistência médico-hospitalar por um lado, e, por outro, abrangeu em suas instituições modelos distintos de atenção, ainda que com pesos e recursos desiguais. $\mathrm{Na}$ seção sobre o movimento sanitário, a implementação concreta de programas alternativos à assistência médico-hospitalar evidenciarão esta última tendência.

\section{Movimento sanitário}

O movimento sanitário no Brasil é um ator coletivo que se constituiu ao longo dos anos 1970, a partir dos Departamentos de Medicina Preventiva, e, paulatinamente, foi abarcando diversos segmentos dos profissionais de saúde - médicos organizados em sindicatos, movimento estudantil de medicina e academia, conformando um movimento de médicos e intelectuais de formação comunista, socialista e liberal (Escorel, Nascimento e Edler, 2005, p. 68; ver também Escorel, 1998, p. 193; Barros, 2002, p. 23; Fleury, 1991). Até 1979, guiado pelo ideal médico-social e pautado na aguda crítica do modelo de saúde do regime militar, o movimento atuou em alguns projetos e programas, limitados em termos de abrangência, mas que permitiram acumular a experiência e 
aglutinar seus integrantes. Esta atuação fazia parte da opção pela atuação reformista nas instituições públicas de saúde, que se intensificou no início dos anos 1980.

O movimento cresceu e consolidou-se em torno de alguns espaços e instituições. O primeiro e importante espaço comum a esses atores foi a Semana de Estudos sobre Saúde Comunitária, realizada anualmente desde 1975, e que proporcionava possibilidade de discussão e debate por não sofrer uma atenção repressora do regime militar. A partir de 1979, fortaleceu-se a atuação de instituições novas voltadas para a pesquisa, debate e difusão das propostas como o Centro Brasileiro de Estudos da Saúde (Cebes), constituído em 1976, que desempenhou, por meio de sua revista Saúde em Debate, um papel importante na divulgação de propostas e promoção de debates. O Cebes conseguiu uma importante capilaridade, ao abrir núcleos regionais espalhados pelo Brasil. O núcleo de Brasília, por exem194 plo, trabalhou com os parlamentares, o que resultou, entre outros, na organização dos Simpósios da Política Nacional de Saúde, nos quais o movimento apresentava e debatia suas propostas de reforma.

Em termos dos espaços de perfil mais acadêmico, cabe destacar a Associação Brasileira de Pós-Graduação em Saúde Coletiva (Abrasco), fundada em 1979, que foi uma importante parceira do Cebes, e o Instituto da Medicina Social da Universidade Estadual do Rio de Janeiro. O movimento sindical médico, por sua vez, ao renovar suas entidades de representação, tornou-se bastante ativo na organização da categoria (Lima, Fonseca e Hochman, 2005; Escorel, 1998; Cordeiro, 1991; Cohn, 1989).

A estratégia de ocupação de espaços também incluía a escolha da "via do parlamento". Já a partir das vitoriosas eleições para o partido da oposição de 1974, elegeram-se vários parlamentares identificados seja com o próprio movimento, seja com a democratização que eram pauta comum 
para diversos setores. A Câmara de Deputados e sua Comissão de Saúde foram aproveitadas para o debate público ou até para a organização do movimento na base de apoio dos parlamentares e da infraestrutura da própria Comissão (Rodrigues Neto, 1997, p. 64). Havia também o investimento do movimento para a eleição de parlamentares federais e estaduais como também de prefeitos e vereadores comprometidos com o movimento.

Ainda que não fosse a única tendência no movimento sanitário, a opção pela atuação reformista no interior das instituições do Estado dirigidas pelo regime militar pôde ganhar uma importância na medida em que, a partir de 1975, a área social, conforme já mencionado, foi priorizada. O regime militar criou novas instituições e programas e, na falta de quadros próprios para preencher esses novos espaços, abriram-se portas para os profissionais comprometidos com um projeto de saúde adverso ao existente (Escorel, Nascimento e Edler, 2005, p. 66). Constituiu-se uma relação mutuamente reforçadora: a burocracia progressista se apropriava das propostas do governo para fazer avançar as suas, que iam contra o modelo principal, enquanto o próprio regime utilizava o desenvolvimento das propostas progressistas, seja para sua legitimação, seja para a implementação de medidas racionalizadoras (Escorel, 1998, p. 182; Arretche, 2005, p. 291).

Em três projetos desenvolvidos na década de 1970, o movimento sanitário pôde colocar em prática algumas de suas principais bandeiras como universalização, acessibilidade, descentralização, integralidade e participação comunitária (Escorel, 1998, p. 133): o Plano de Localização de Unidade de Serviços (Plus), o Sistema Integrado de Prestação de Serviços de Saúde no Norte de Minas Gerais (chamado de Projeto Montes Claros) e o Programa de Interiorização de Ações de Saúde e Saneamento (Piass). O Plano de Localização, criado em 1975 com o objetivo da elabora- 
ção de planos de saúde para as regiões metropolitanas, foi concebido numa conjuntura da Previdência Social marcada pela modernização administrativa e planejamento racionalizador. O grupo técnico convocado para realizar o Plus, na falta de quadros próprios na previdência, foi composto pelos profissionais de diversas áreas da burocracia estatal, ligados por um comum ideário da medicina social. Com fartos recursos financeiros e projeção nos estados, o "grupo do Plus" gerou uma forte oposição na VI Conferência Nacional de Saúde (1977), que resultou na interrupção do Plano em abril de 1979 e na dispersão de seus integrantes. Sua menção deve-se ao fato de ele ter sido a primeira experiência comum dos profissionais identificados com a reforma no âmbito da assistência médica previdenciária e como exemplo de possibilidade de planejamento alternativo dentro da previdência (Escorel, 1998, pp. 135-142).

O Projeto Montes Claros, por sua vez, iniciou-se em

1961971 e terminou em 1978 e constituiu a primeira experiência e demonstração dos princípios defendidos pelo movimento sanitário na prática. O projeto propunha integrar todas as ações de saúde, tanto as curativas quanto preventivas, numa estrutura hierarquizada, introduzindo-se o princípio de participação comunitária. A importância deste projeto para o movimento sanitário decorre do fato de congregar os integrantes, promover discussões e ser objeto de investigação acadêmica. Apesar da grande mobilização de setores reformistas, por pressão do setor privado, o projeto foi reduzido a um sistema de atenção primária, mas constituiu uma experiência local importante para o próximo projeto do movimento sanitário, o Piass.

O Piass de 1976 foi um programa que ilustra a mudança das tendências setoriais rumo à abordagem médico-social e evidencia a crescente capacidade de incidência do movimento na política. O Piass é considerado o exemplo mais emblemático do encontro entre o movimento sanitário e a 
tecno-burocracia. Pelo lado das instituições responsáveis, o programa simplificava o cuidado e serviço oferecidos, baixando os custos (Bodstein e Fonseca, 1989); enquanto na ótica do movimento sanitário, o programa conseguia propiciar um "expressivo incremento na oferta de serviços ambulatoriais básicos a populações completamente excluídas do acesso a equipamentos sociais, em especial no Nordeste" (Noronha e Levcovitz, 1994, p. 79), integrando as ações preventivas com as curativas e incentivando a participação popular. E se, ao contrário da proposta inicial de oferecer o acesso a todos os níveis de atendimento, viabilizou-se apenas uma rede de minipostos focalizada na atenção primária, atingiu-se um alto índice da cobertura - 56\% da população nos estados onde foi implementado (Escorel, 1998, p. 168).

O Piass significou o fortalecimento do setor público de saúde na medida em que as Secretarias Estaduais de Saúde se tornaram responsáveis por seu gerenciamento e implementação e, em 1979, obteve o financiamento do Instituto Nacional de Assistência Médica e Previdência Social (Inamps) - agência federal responsável pela assistência médico-hospitalar e reduto dos interesses privados.

\section{Profissionais de saúde e oportunidades institucionais}

Em 1981, eclodiu a crise financeira do sistema previdenciário que financiava a saúde, trazendo à tona o esgotamento desse modelo de financiamento ${ }^{5}$. Com o objetivo de interferir nesse quadro, o regime militar, na pessoa do Presidente

\footnotetext{
${ }^{5}$ As contas negativas da previdência deviam-se à extensão de seus benefícios a contingentes mais amplos da população, sem que se garantissem novos mecanismos de financiamento. O sistema era sustentado fundamentalmente pelos assalariados urbanos e suas folhas de pagamento, recurso que diminuiu drasticamente no quadro recessivo da economia da época. O déficit da previdência foi também atribuído ao desvio de recursos para a construção da infraestrutura (Arretche, 2005, p. 291). Por outro lado, havia o descontrole de gastos com a assistência médico-hospitalar.
} 
da República, constituiu, no mesmo ano, o Conselho Nacional de Administração da Saúde Previdenciária (Conasp), composto pelos representantes dos principais atores setoriais: segmento privado de saúde, tecno-burocracia e reformistas (Cordeiro, 1991). O Conselho elaborou o Plano de Reorientação da Assistência à Saúde no Âmbito da Previdência Social, conhecido como o Plano do Conasp (aprovado em agosto de 1982), no qual foram reconhecidas as distorções do modelo da organização de saúde promovido pelo Inamps e previstas 17 medidas de caráter racionalizador com o objetivo de sanear a situação por meio da redução de custos (Gallo, 1988, p. 77; Barros, 2002, p. 20; Cordeiro, 1991, p. 31). Um exemplo que ilustra esse tipo de medidas foi a reformulação das relações com os prestadores privados contratados pelo Inamps por meio do Sistema de Assistência Médico-Hospitalar da Previdência Social, que passou a remunerar os procedimentos médico-cirúrgicos não mais

198 pela soma de atos médicos fragmentados realizados em um dado paciente, que abria uma ampla margem para a corrupção, mas pelo valor médio, estabelecido a priori, do procedimento na sua totalidade.

No entanto, a medida mais duradoura e importante do Plano do Conasp foram as Ações Integradas de Saúde (AIS) que expressavam de forma mais evidente as propostas do movimento sanitário. As AIS anunciavam, em 1983, nada menos que a alteração da atenção à saúde, ao conter princípios da universalização de acesso, descentralização, participação comunitária, regionalização e hierarquização das ações e maior participação dos prestadores públicos (Fleury, 1991, p. 78; Escorel, Nascimento e Edler, 2005, p. 75). As AIS consistiam, na prática, no repasse de verbas do Inamps aos demais níveis federativos, o que reanimou os serviços locais de saúde ou permitiu sua criação, principalmente no nível de atenção básica. O novo sistema promoveu também a integração das ações de prestadores públicos ao criar 
comissões interinstitucionais nos níveis locais, regionais, estadual e federal.

A implementação das AIS foi possibilitada pelo resultado das eleições de 1982 para os governos dos estados e municípios, que levaram ao poder, em diversas partes do país, os partidos da oposição ao regime militar. Com isso, o movimento sanitário intensificou a estratégia de ocupação de espaços nas instituições públicas. Em 1983, por exemplo, vários de seus integrantes estavam entregues às tarefas no poder público, o que resultou na não publicação da principal revista do movimento, Saúde em Debate (Gallo, 1988, p. 77). No período entre 1983 e 1984 os convênios AIS foram assinados com 15 estados e 112 municípios, entre os quais dois importantes: São Paulo e Rio de Janeiro (Paim, 1986, p. 168; Fleury, 1991).

Se as AIS, já no seu formato, atestavam a capacidade de incidência do movimento sanitário na política setorial, seu vertiginoso crescimento ocorreu no governo de transição democrática que sucedeu o regime militar em 1985. Para o setor de saúde, a proposta para o novo governo foi elaborada no V Simpósio da Política Nacional de Saúde na base de documentos da Cebes e reforçava a estratégia das AIS. Os representantes do movimento sanitário assumiram, nesta fase, os postos-chave nas instituições responsáveis pela política de saúde no país, o que resultou na ampliação da implementação - o número de municípios envolvidos nas AIS cresceu para 2.215, em 1986 - e no aprofundamento dos princípios norteadores das Ações (Cohn e Elias, 2005, p. 63; Escorel, 1998, p. 185; Brasil, apud Noronha e Levcovitz, 1994, p. 88; Pimenta, 1993, p. 28).

Em 1987, as AIS foram substituídas por uma proposta ainda mais imponente da descentralização financeira e da subtração do poder do Inamps. O Sistema Unificado e Descentralizado de Saúde (Suds) foi instituído pelo decreto presidencial em 1987, a partir da proposta da presidência 
do Inamps - cargo ocupado na época por um representante do movimento sanitário, Hésio Cordeiro. Tratava-se de uma política de amplitude e abrangência nacional cujas diretrizes reiteravam os princípios da mudança: a descentralização e, mais especificamente, a municipalização dos serviços de saúde; a universalização e equidade no acesso aos serviços de saúde; integralidade dos cuidados assistenciais; regionalização e integração de serviços e desenvolvimento de instituições colegiadas (Lima, Fonseca e Hochman, 2005, p. 79; Noronha e Levcovitz, 1994, p. 88). Com o Suds a participação do setor público nas despesas do Inamps passou de 25,8\% em 1981 (considerada aqui a rede própria do Inamps, os serviços públicos e os hospitais universitários) para 45,2\% em 1987, enquanto a participação do setor privado contratado e conveniado diminuiu de $64,3 \%$ para $40 \%$ nos mesmos anos (Cordeiro, 1991, p. 106). ${ }^{6}$

Em 1988, na promulgação da Constituição, o setor de 200 saúde no Brasil já havia atravessado um longo caminho das reformas que universalizavam o acesso gratuito à saúde e descentralizavam os serviços para os estados e municípios, ainda que mantendo o setor privado como um dos fornecedores de serviços. É importante sublinhar que as mudanças de cunho reformista se processaram no interior da instituição responsável pela assistência médico-hospitalar, diferentemente do que ocorrera com os projetos dos anos 1970 sob a responsabilidade do Ministério de Saúde, e que foram suportadas pelo movimento sanitário, portador de uma clara proposta e atuante nas instituições estatais nos três níveis federativos a despeito das diferenças ideológicas em rela-

\footnotetext{
${ }^{6}$ O Suds perdurou até 1990, isto é, até a aprovação da Lei Orgânica de Saúde (LOS) e, ao longo de sua vigência, enfrentou as resistências do setor privado e da burocracia do Inamps, principalmente quando os representantes do movimento sanitário foram depostos dos quadros dirigentes do MPAS e do Inamps. A continuidade do Suds foi garantida pelo envolvimento e pressão dos secretários estaduais e municipais de saúde (Escorel, 1998, p. 94; Noronha e Levcovitz, 1994, p. 94).
} 
ção aos governos. Desta forma, configurou-se um desenho peculiar da reforma, que contemplou os projetos e interesses dos relevantes atores na arena setorial, sem que fossem aplicados receituários internacionais que, na época, consistiam na privatização ou enxugamento de gastos públicos.

Enquanto no plano federal, os representantes do movimento sanitário estavam encaminhando programas reformistas, o movimento pela saúde crescia e aglutinava novos atores. Um marco simbólico de novas alianças foi constituído pela $8{ }^{a}$ Conferência Nacional de Saúde da qual participaram pela primeira vez os usuários, ainda que a coordenação e a condução do evento fosse prerrogativa do movimento sanitário (Vilaça, 1995, apud Goulart, 1996, p. 68). A partir de então, as propostas da Reforma Sanitária começaram a ser elaboradas por um conjunto mais amplo de atores organizados em Plenária Nacional de Entidades de Saúde, composta por representantes do movimento popular, do movimento sindical, dos profissionais da saúde, dos partidos políticos, de representantes da academia e representantes dos trabalhadores, com o intuito de elaborar o texto que informaria os trabalhos na Constituinte.

Ainda que a literatura ressalte os interesses contrários do setor privado às propostas da Reforma Sanitária, é importante destacar que estas, já a partir da 8. ${ }^{a}$ Conferência, não continham mais a ideia da estatização setorial, embora houvesse grupos do movimento que a apoiavam fortemente como, por exemplo, o Partido dos Trabalhadores (Rodrigues Neto, 1997, p. 69). As negociações em torno do perfil do setor público de saúde durante a Assembleia Constituinte entre os representantes da Reforma Sanitária e o setor privado resultaram em um desenho factível para ambas as partes $^{7}$ e no mais avançado entre todas as políticas sociais.

\footnotetext{
${ }^{7}$ Nos trabalhos da Constituinte a questão da estatização foi ainda apresentada pelos integrantes do PT sem ser, no entanto, a grande bandeira de luta.
} 
O texto da Constituição sobre o setor de saúde abrangeu os postulados do movimento pela Reforma Sanitária - sistema unificado e hierarquizado, descentralizado, pautado na participação da comunidade e atendimento integral - e garantiu a continuidade da atuação do setor privado como prestador complementar de serviços públicos e com a liberdade para a expansão do mercado privado de medicina ${ }^{8}$. A contemplação dos interesses dos principais atores societários naquele momento resultou no avanço das reformas nos anos 1990, repetindo a dinâmica das reformas a partir do início da década de 1980, conforme discutido na seção anterior.

\section{Negociando a implementação do SUS}

A análise do setor de saúde no período posterior à Constituição realça a institucionalização dos principais atores decorrente da redemocratização do país, do novo pacto

202 federativo, do desenho do SUS e da nova configuração dos atores com interesse e capacidade de incidir na política setorial e levar as reformas adiante.

Os termos e resultados da implementação do sistema indicam o papel preponderante do Ministério da Saúde e dos secretários municipais de saúde nas negociações em torno das reformas. Ambos foram responsáveis pela elaboração das normas que operacionalizavam o SUS: o MS, como órgão executivo editor das normas, e os secretários, institucionalizados numa organização nacional, como partícipes ativos no seu desenho. Em 2002, 99,6\% dos municípios aderiram ao SUS (Arretche, 2003, p. 333), evidenciando uma tendência clara: $90 \%$ tornou-se responsável pela gestão da

\footnotetext{
${ }^{8}$ Ficou definido que a "assistência à saúde é livre à iniciativa privada" e que "as instituições privadas poderão participar de forma complementar do sistema único de saúde, segundo diretrizes deste, mediante contrato de direito público ou convênio, tendo preferência as entidades filantrópicas e as sem fins lucrativos" (Brasil, 1988, art. 199 - grifo nosso).
} 
atenção básica, adotando maciçamente dois programas desenhados pelo governo federal para esse nível de atenção, o Pacs e o PSF. Em 2002, 4.161 dos 5.560 municípios possuíam as equipes do PSF implementadas (DAB, 2007), dando cobertura a 54,9 milhões de pessoas do total de 140 milhões SUS dependentes.

\section{Nova configuração de atores após 1988}

A Constituição de 1988 promoveu o município à condição do ente federado, dotado, portanto, de autonomia e, em termos de competências intergovernamentais, previu que a prestação de serviços de atendimento à saúde da população fosse de competência exclusiva municipal ${ }^{9}$ (Brasil, 1988, art. 30), cabendo à União e aos estados a cooperação técnica e financeira necessária ao desempenho daquela função pelo município. Ou seja, o município se tornou o principal espaço de implementação do SUS, dependente, em grande parte, dos recursos federais, mas autônomo, a priori, no que se refere à sua aplicação. A nova posição do município se refletiu no fortalecimento do peso político dos secretários municipais de saúde e de sua organização de representação na arena setorial do Ministério de Saúde.

Os secretários municipais de saúde, que expressavam a voz dos municípios, vinham se mobilizando desde o início dos anos 1980, ao se reunir regionalmente, e tornavam públicas suas posições por meio de cartas-manifesto, sem ter, no entanto, expressão forte na política setorial. Esse fato pode ser evidenciado por sua posição marginal na $8 .{ }^{a}$ Conferên-

\footnotetext{
${ }^{9}$ O texto da Constituição não distinguiu os níveis de atenção - básico, médio e complexo - referindo-se genericamente aos serviços de saúde. Esta indistinção foi explicitada na Norma Operacional Básica (NOB) de 1996, que definiu a capacitação dos municípios para a regulação de todos os prestadores de serviços, sejam eles públicos ou privados. A Norma Operacional de Assistência à Saúde (Noas) de 2001 reverteu esta tendência, ao reservar à União e aos estados a gestão da média e alta complexidade (Arretche, 2003, p. 337).
} 
cia, em 1986, e a não publicação de sua carta no relatório do evento (Goulart, 1996, p. 22). Naquela época, vale lembrar, o desenho federativo distinguia apenas o estado como ente dotado de autonomia, e os programas de saúde o focalizavam como parceiro dos órgãos federais. Não é acidental que os secretários estaduais possuíam um poder de negociação importante na política, e sua organização, o Conselho Nacional de Secretários de Saúde (Conass), esteve presente de forma expressiva em momentos cruciais das reformas do setor. ${ }^{10}$

A institucionalização do movimento dos secretários municipais de saúde por meio da constituição do Conselho Nacional de Secretários Municipais de Saúde (Conasems) ocorreu ao mesmo tempo da promulgação da Constituição em 1988. Organizados nacional e regionalmente e amparados pela prerrogativa da autonomia municipal a partir de então os secretários assumiram um dos principais lugares

204 na negociação setorial. Do período da regulamentação do SUS (1988 a 1991), destaca-se a pressão bem sucedida exercida por eles diante dos vetos do presidente Collor a uma série de artigos da Lei Orgânica de Saúde, nº 8.080, entre os quais a participação deliberativa da comunidade por meio dos conselhos e conferências, que era um dos pilares da proposta da reforma sanitária, e a transferência automática de recursos do federal aos estados e municípios que viabilizaria a decisão autônoma dos níveis subfederativos sobre a política local de saúde. Esses vetos infringiam os princípios constitucionais do SUS, e o Conasems iniciou uma mobilização da sociedade civil e segmentos do poder público que resultou na negociação direta com o MS para elaborar uma

\footnotetext{
${ }^{10} \mathrm{O}$ Conass foi responsável, por exemplo, pela elaboração de um dos dois documentos que informaram o plano do setor de saúde do primeiro governo após a ditadura, em 1985, e sua pressão foi indispensável para a manutenção do Suds, caracterizado como estadualização de saúde.
} 
proposta alternativa para a lei. Foi a sua pressão ao Ministério da Saúde que levou o Ministro a declarar, publicamente, no encontro do Conasems de Fortaleza, seu compromisso com a causa e levou à aprovação da Lei 8.142 no final de 1990, que complementou a 8.080, formando a Lei Orgânica de Saúde.

Ainda durante o mandato de Collor, no prenúncio de seu impeachment, os secretários foram incumbidos da organização e condução da 9. ${ }^{a}$ Conferência (seis anos depois da histórica 8. ${ }^{a}$ Conferência) cujo título marca a pauta de sua negociação: "Saúde: municipalização é o caminho". A partir de então, sua capacidade de incidência na política setorial pôde ser observada por meio das normas emitidas pelo MS que operacionalizavam a implementação do SUS.

O movimento sanitário, que se destacou na promoção das reformas ao longo dos anos 1980, na nova conjuntura, sofreu processo de fragmentação e reconfigurou suas formas de atuação. Os sindicatos se voltaram mais para suas lutas corporativas, e os pesquisadores centraram suas atividades na produção de conhecimento (Escorel, 1998). Uma parte dos seus integrantes se inseriu na vida política, seja como executivos de governos no Ministério de Saúde e nas Secretarias Municipais de Saúde, seja nas casas legislativas em três níveis federativos. Embora sem pesquisas que demonstrem com rigor sua atuação política, podese afirmar com certo grau de segurança que médicos e médicas, enfermeiros e enfermeiras ligados à Reforma Sanitária e com a experiência acumulada nos anos 1970 e 1980 ocuparam cargos públicos no setor em três níveis federativos.

O setor privado, por sua vez, na condição do prestador complementar de serviços para o Estado, continuou concentrado primordialmente na atenção hospitalar, sendo responsável, em 2002, por $63 \%$ dos leitos oferecidos no 
SUS (Ugá e Marques, 2005, p. 194). Em termos relativos, sua presença espelha a distribuição dos leitos de 1975, que era de $32 \%$ públicos contra $68 \%$ privados (Barros e Porto, 2002, p. 10), em plena vigência do modelo de assistência médico-hospitalar oferecida pelo MPAS à sua clientela contribuinte. Esse dado demonstra a importância da presença do prestador privado no SUS, que o torna um ator com interesses semelhantes, em parte pelo menos, aos interesses daqueles que o combatiam ferozmente, incrementando as fileiras dos defensores do SUS em momentos de importantes barganhas. ${ }^{11}$ Por outro lado, o setor privado ampliou significativamente a parcela de sua clientela privada, que compra os serviços de saúde por meio de planos, seguros ou compras eventuais: entre 1987 e 1998 o número de clientes cresceu em torno de 70\% (Barros, 2003, p. 25) e abrange, atualmente, por volta de $25 \%$ da população brasileira dos quais $75 \%$ com o rendimento superior a 5 salários mínimos 206 (Opas, 2005, p. 20).

Os usuários de saúde, a tal chamada comunidade, agrupados em diversas formas organizacionais e que surgiram no palco nacional na 8 . $^{\text {a }}$ Conferência, tiveram sua participação institucionalizada por meio dos conselhos instalados em três níveis federativos, obrigatórios por lei e aos quais cabe a formulação de estratégias e controle da execução das

\footnotetext{
${ }^{11}$ A Federação Brasileira de Hospitais, por exemplo, ator de relevância no setor privado na década de 1970 e cujos associados executam hoje $62 \%$ dos procedimentos oferecidos pelo SUS, explicita com todas as letras sua preocupação com a trajetória do SUS, enfocando a importância da atuação de hospitais privados associados à Federação no Sistema. Sua adesão ao SUS pode ser expressa no seguinte trecho: "Nas discussões para aprovar a nova Constituinte, a FBH manteve seu canal de negociação com os parlamentares, trabalhando para que população e hospitais, públicos e privados, fossem tratados com respeito. A articulação foi de extrema importância para ajudar a definir o capítulo referente à Saúde, que foi aprovado em comum acordo, sem que fosse necessária a realização de votação. Com a criação do Sistema Único de Saúde (SUS), o novo texto constitucional mostrou estar alinhado a um novo modelo de saúde que buscava resgatar o compromisso do estado com o bem-estar social" (FBH, 2008).
} 
políticas (Escorel, Nascimento e Edler, 2005, p. 85). Conquistaram $50 \%$ dos assentos nos conselhos, compartilhados com outros setores como trabalhadores de saúde e governo. Um outro espaço que organiza a participação dos usuários são as conferências municiais, estaduais e nacional de saúde cuja prerrogativa é de propor diretrizes para a formulação de políticas.

\section{A municipalização do SUS}

Ao analisar os termos da implementação do SUS nas décadas de 1990 e 2000 pelo prisma da negociação entre os principais atores destaca-se a intensa interação entre o MS e os municípios. Os resultados mais evidentes da implementação consistiram na municipalização do SUS via atenção básica e adoção de programas federais deste nível de atenção pelos municípios e indicam a efetividade dessa interação nos termos interessantes para ambos os lados. Os municípios, organizados em uma forte organização de representação e contando com espaços efetivos de negociação, não contestaram as regras propostas pelo MS, como o fizeram com sucesso na época dos vetos presidenciais em 1990 à Lei Orgânica de Saúde. Sua capacidade de incidir na política fica evidenciada quando se leva em consideração a escassa discussão sobre esses programas federais nos espaços institucionalizados de participação que agregam outros atores importantes do setor como usuários e sindicatos.

Após a promulgação da LOS pelo poder legislativo, as principais regulamentações do setor (Normas Operacionais Básicas 1991, 1992, 1993, 1996) foram elaboradas e publicadas pelo MS e resultaram na implementação do SUS na totalidade dos municípios em 2002. O resultado do processo consistiu primordialmente na municipalização da atenção básica, adotada por 99,6\% dos municípios dos quais apenas $10 \%$ se responsabilizaram pela gestão plena do sistema municipal (Arretche, 2003, p. 33), fortemente apoiada 
em dois programas federais - o Pacs e o PSF. ${ }^{12}$ O PSF, que se diferencia do Pacs por incluir na equipe de atendimento, médico, enfermeiro e auxiliar de enfermagem, além dos agentes comunitários, abrangeu em torno de $47 \%$ da população em 2007, em mais de cinco mil municípios (Dab, 2007).

Por um lado, tal resultado pode ser explicado pela capacidade de negociação do MS decorrente da função da coordenação do processo como também de sua função de financiamento. Até 1990, os recursos de origem federal representavam $77,7 \%$ do total do gasto público com saúde e, ainda que essa presença assumisse uma tendência decrescente em função de maior comprometimento do nível municipal, a participação da verba federal manteve-se elevada ao longo da década: 60,7\% em 1994; 53,7\% em 1996 e 58,3\% em 2000 (Ugá e Marques, 2005, p. 216). É importante lembrar que, apesar do incremento da quota dos municípios no conjunto das receitas públicas que, quando somadas, as receitas tribu208 tárias próprias e as transferências constitucionais passaram de 10,8\% em 1988 para 16,9\% em 2000; com a exceção de capitais e grandes cidades, a arrecadação própria é inferior às transferências constitucionais que recebem da União ou dos estados. Em 1997, as transferências federais e estaduais constituíram mais de $50 \%$ da receita de 4.876 cidades (Bndes, 2001, p. 2).

Por outro lado, os termos da implementação do SUS nos estados e municípios e o posicionamento dos atores

\footnotetext{
${ }^{12}$ O Programa da Saúde da Família consiste em equipes compostas, no mínimo, por um médico de família, um enfermeiro, um auxiliar de enfermagem e seis agentes comunitários de saúde. "Quando ampliada, conta ainda com: um dentista, um auxiliar de consultório dentário e um técnico em higiene dental. Cada equipe se responsabiliza pelo acompanhamento de cerca de 3 mil a 4 mil e 500 pessoas ou de mil famílias de uma determinada área, e estas passam a ter co-responsabilidade no cuidado à saúde" (Dab, 2008). O Programa de Agentes Comunitários de Saúde, por sua vez, apoia-se no trabalho de agentes comunitários de saúde que são acompanhados e orientados por um enfermeiro/supervisor lotado em uma unidade básica de saúde. O Pacs é considerado um programa de transição para o PSF (Dab, 2008).
} 
apontam a relevância dos secretários municipais de saúde nessas barganhas. A primeira NOB, a de 1991, foi elaborada pelo MS durante o governo de Collor, sem a participação dos demais atores do setor, e reproduziu formas de relacionamento anteriores ao desenho legal do SUS regulamentado pela Lei Orgânica de Saúde. A definição do tipo de repasse de recursos, que privilegiou o pagamento por produção de serviços ${ }^{13}$ em detrimento do perfil epidemiológico do município e a classificação do setor público e do privado na mesma categoria de prestadores de serviços a serem remunerados pelos recursos federais constituíram dois exemplos desse viés. A NOB seguinte, a de 1992, já foi negociada com o Conasems e o Conass, e o representante do Conasems assumiu o departamento do SUS na Secretaria da Assistência à Saúde do MS. Ainda assim, a adesão ao SUS pode ser considerada baixa: na sua vigência, somente 1.074 municípios aderiram a esta norma. O que pode explicar essa baixa adesão é a insegurança de recursos - em 1993 houve a crise de desfinanciamento por falta de repasse na ordem de $30 \%$ do Ministério de Previdência ao de Saúde (Barros, 2002).

A NOB de 1993 originou-se de um processo distinto, mais participativo, e resultou no aumento de adesões. O novo ministro de saúde, Jamil Haddad, vinculado ao movimento sanitário, reestabeleceu os canais de negociação com os demais atores ao convocar o Grupo Especial de Descentralização, composto por representantes do Ministério de Saúde, secretários de saúde dos estados e municípios e Conselho Nacional de Saúde. O documento elaborado pelo grupo, intitulado "Descentralização da Saúde: a ousadia de cumprir e fazer cumprir a lei” informou o conteúdo dessa NOB.

\footnotetext{
${ }^{13} \mathrm{O}$ pagamento dar-se-ia por meio da apresentação da fatura de atos executados mensalmente pelas unidades de saúde. Esta forma de financiamento foi encarada como uma limitação à autonomia, visto que as transferências estavam vinculadas a um dado tipo de atuação definido a priori pelo nível federal.
} 
O desenho da descentralização ficou factível: ofereceu aos estados e municípios a possibilidade de adesão ao SUS por meio de três níveis de habilitação, cada qual para um tipo de capacidades administrativas e gestão. A NOB obteve bons resultados: a adesão dos municípios aumentou consideravelmente, comparada com a taxa de adesão à NOB anterior, respectivamente, quase $63 \%$ em 1996, contra $22 \%$ em 1993 (Arretche, 2001, p. 447). A adesão se deu essencialmente no nível de atenção básica, e somente 144 municípios aderiram à gestão de maior complexidade (Arretche, 2005, p. 298).

Foi nessa NOB que os secretários municipais conseguiram impulsionar a instalação de espaços formais de negociação e deliberação intergovernamental. Foi instituído um espaço intergovernamental de negociação no nível estadual, a Comissão Intergestores Bipartites (CIB), que institucionalizava o direito à voz dos municípios na definição das regras

210 da descentralização. A CIB foi instituída como espaço transitório convocado para um determinado fim, mas se firmou ao longo dos anos como espaço em que são discutidas

"praticamente todas as questões que dizem respeito ao financiamento, à descentralização da estrutura gestora do SUS e à estruturação e funcionamento do sistema de saúde propagados pelo nível federal e/ou estadual" (Levcovitz, Lima e Machado, 2001, p. 278).

Foi ativada também a Comissão Intergestores Tripartite (CIT) (criada já em 1991, mas que não foi consultada durante o governo Collor) como espaço de negociação entre os três entes federados no nível federal (Arretche, 2005; Levcovitz, Lima e Machado, 2001).

A NOB 01/1993, por fim, consolidava a institucionalização dos representantes de grupos organizados e/ou usuários na formulação, acompanhamento e controle social 
da política do setor ao condicionar a habilitação ao SUS dos estados e municípios à instalação dos Conselhos de Saúde.

A discussão em torno da NOB 01/1996 repetiu o caráter de negociações da NOB anterior, estendendo de seis para doze meses o processo de barganhas. Salienta-se que o texto original foi mudado depois pelo Ministério da Saúde por meio de portarias, e a mudança mais importante inserida após a negociação com os demais atores refere-se à fragmentação das transferências, isto é, sua vinculação aos programas definidos e regulamentados pela instância federal (Levcovitz, Lima e Machado, 2001, p. 282). Esse mecanismo já estava visível na própria NOB, justamente no nível de atenção básica. Para os municípios habilitados no SUS foi instituído o Piso de Atenção Básica (PAB), divido em uma parte fixa (per capita) e um incentivo, chamado depois de $\mathrm{PAB}$ variável, condicionado à adoção pelo município dos programas federais - o Programa de Agentes Comunitários de Saúde e do Programa de Saúde de Família - ou de outra estratégia similar a ser avaliada pelo Ministério de Saúde. O incentivo, menor para o Pacs e maior para o PSF, funcionava da seguinte forma no caso do PSF: para cada $5 \%$ da população coberta pelo programa, o município ganhava um acréscimo de $3 \%$ sobre o valor do PAB fixo até atingir $60 \%$ da população total do município; um acréscimo de $5 \%$ para cada $5 \%$ da população coberta entre $60 \%$ e $90 \%$ da população total do município; e um acréscimo de $7 \%$ para cada $5 \%$ da população coberta entre $90 \%$ e $100 \%$ da população total do município (Nob, 1996, p. 20). O teto para esses acréscimos era de $30 \%$ do PAB fixo.

O MS conseguia, por meio desse desenho, um incentivo adicional para a implementação da atenção básica, ao mesmo tempo em que esse incentivo servia como incentivo à adesão ao SUS. Para que pudesse ser firmado o convênio 
entre o MS e o município exigia-se deste último a comprovação do funcionamento do Conselho Municipal de Saúde, da operação do Fundo e, obviamente, a adesão ao SUS. A resposta dos municípios em termos da adesão superou as metas do próprio Ministério de Saúde. Em maio de 2002, 5.537 dos 5.560 dos municípios já estavam habilitados na NOB 1996 (que começou a ser implementada, de fato, a partir de 1998), sendo 4.973 na condição da gestão plena da atenção básica e 564 na gestão plena do sistema municipal $^{14}$ (Arretche, 2003, p. 33). A adoção dos dois programas, o Pacs e o PSF, também deslanchou: de 567 municípios com as equipes do PSF em 1997 passou-se para 1.134 no primeiro ano da implementação da NOB 1996, para $4.161 \mathrm{em}$ 2002 quando 99,6\% dos municípios já estavam habilitados no SUS, e, em 2007, para 5.131. Em termos da cobertura da população, em 1997, havia 5,6 milhões de pessoas cobertas pelas equipes do PSF; em 2002, havia 54,9 e, em 2007, 87,9

212 (Dab, 2007).

As transferências para a atenção básica como todo refletem também um crescimento vertiginoso de investimentos: de 2.213.9 bilhões em 2000 para 7.034 em 2007 - quase $300 \%$ de crescimento. A inflexão pela implementação da atenção básica nos municípios via programas federais se expressa também pela distribuição de recursos entre o PAB fixo e o PAB variável (condicionado à adoção dos programas). No período de 2000 a 2007, o fixo cresceu $100 \%$ e o variável 600\%; em números absolutos, o valor do primeiro ficou abaixo do segundo: 2.97 bilhões contra 4.064 bilhões, respectivamente (Dab, 2007).

Em resumo, a implementação do SUS, que se processou primordialmente pela municipalização da atenção bási-

\footnotetext{
${ }^{14}$ A partir de 2000, o setor de saúde tornou-se menos vulnerável à política macroeconômica na medida em que foi aprovada a Emenda Constitucional 29, que assegurou percentuais fixos para os estados e municípios, de 12 e $15 \%$, respectivamente, a serem atingidos, a partir de 2004 (Barros, 2002, pp. 30-31).
} 
ca marcada fortemente pela adoção de programas federais desse nível de atenção, foi conduzida no nível federal pelo MS em processo de negociação com a instância de negociação intergovernamental na qual estavam presentes as organizações de secretários municipais e estaduais de saúde. O processo ocorreu, portanto, entre os atores institucionalizados, e tanto os termos como resultados, parecem corroborar o argumento das negociações bem sucedidas entre o MS e os secretários municipais de saúde. O jogo de barganhas incluiu o desenho factível e os incentivos financeiros para adoção da atenção básica pelos municípios que o fizeram, adotando maciçamente programas federais desse nível de atenção.

Se a demanda pela municipalização do SUS englobava diversos atores do setor, a adoção e massificação dos programas federais de atenção básica não absorveram muitas energias dos participantes nas Conferências Nacionais de Saúde e no Conselho Nacional de Saúde. Ao analisar as conferências por meio de seus relatórios, a 9a edição, em 1992, sugeria, genericamente, a necessidade de mudança do modelo assistencial sem indicar propostas concretas para a atenção básica, apesar da expansão do Pacs em curso. Na 10. a , apareceu a recomendação do debate entre as secretarias estaduais e municipais e os conselhos para evitar uma implementação central e vertical e insistiu-se na sua integração ao sistema municipal de saúde para evitar o paralelismo de ações e atendimento simplificado. As duas conferências realizadas na década de 2000 avaliaram o Pasf e o Pacs como uma alternativa de atenção básica e detalharam com mais cuidado as recomendações, sem, no entanto, refutar ou endossar de forma decisiva a estratégia. A atenção dedicada pelo Conselho Nacional de Saúde aos programas é quase inexistente quando se analisam as principais resoluções no intervalo de 1992 a 2007: a questão do PSF aparece uma única vez, referindo-se ao apoio do CNS para a implemen- 
tação do PSF e Pacs no distrito federal ${ }^{15}$ (CNS, 2007). Para o setor privado tradicional, por sua vez, fornecedor dos serviços hospitalares, a discussão da atenção básica não representou a priori possibilidades de atuação.

\section{Conclusão}

Analisar o setor de saúde pelo prisma de principais episódios de interação entre os relevantes atores do setor de saúde permitiu indicar a inflexão anterior à Constituição de 1988. Os profissionais de saúde, aglutinados sob a égide do movimento sanitário, aproveitaram as oportunidades institucionais existentes no regime militar para promover programas nacionais de cunho reformista, tornando-se atores de relevância para disputar o desenho constitucional para o setor. No período posterior à Carta Magna, foi possível evidenciar a municipalização da atenção básica fortemente marcada pela adoção de programas federais como a for214 ma de levar a implementação do SUS ao cabo na base de negociação entre o nível federal e os municípios. A segunda interpretação destaca a reconfiguração de atores no palco setorial decorrente da redemocratização, novo desenho federativo e desenho do próprio SUS, mostrando que os atores responsáveis pela reforma não foram os mesmos que a levaram adiante.

A trajetória do setor de saúde no Brasil no que se refere aos seus resultados, analisados pelo prisma de atores com a capacidade de incidir na política, instiga algumas indicações no que se refere ao processo de reformas bem sucedidas no setor público. Sem desconsiderar a legitimidade e força da conquista constitucional do direito universal à saúde, a

\footnotetext{
${ }^{15}$ É sintomática dessa posição, parcialmente alheia, a chegada do PSF no município de São Paulo, um dos últimos a aderirem ao SUS, em 2001. O estudo de caso realizado pela autora deste artigo revela a falta inicial de conhecimento sobre o programa e o posicionamento ambíguo dos principais atores presentes na política setorial: os usuários e principais sindicatos.
} 
implementação do SUS, na contramão das reformas redutoras de políticas sociais e da presença do Estado defendidas pelas agências internacionais e implementadas pelo governo brasileiro em meados da década de 1990, ganha uma chave explicativa adicional quando se demonstra o início das reformas anterior à Constituição.

Outro ponto diz respeito à estratégia dos profissionais reformistas de saúde que consistiu em aproveitar as oportunidades institucionais no quadro do regime militar e resultou na promoção de amplas reformas, tais como as Ações Integradas de Saúde e o Sistema Único e Descentralizado de Saúde, anteriores às garantias constitucionais. A presença e experiência dos integrantes do movimento adquiridas ao ocuparem importantes e influentes posições nas instituições setoriais permitiu que estes assumissem cargos no poder público ao longo dos anos 1990 e 2000. Como exemplos apenas ilustrativos dessa inserção, pode-se citar Roberto Gouveia, Carlos Neder ou Eduardo Jorge, no legislativo, ou Adib Jatene, como Ministro da Saúde.

Vale ressaltar também outra característica peculiar das reformas em foco, que consistiu na concessão dos interesses dos principais atores societários presentes na arena setorial, outrora incompatíveis e antagônicos, e o que assegurou razoável frente de apoio para a implementação do SUS (Arretche, 2005). A expressão mais sintomática da agregação dos interesses é a não estatização do setor público, a despeito das críticas agudas dos integrantes do movimento sanitário ao setor privado de medicina no Brasil ao longo do regime militar. Em termos de consequências, as barganhas para melhorar o financiamento do SUS travadas ao longo das últimas duas décadas envolveram não somente os defensores tradicionais do setor público, mas também os prestadores privados, responsáveis por $63 \%$ de serviços hospitalares prestados no SUS. 


\section{Monika Dowbor}

é pesquisadora do Cebrap; doutoranda do Departamento de Ciência Política da USP

\section{Referências bibliográficas}

ARRETCHE, M. 2000. "O SUS e a municipalização da política nacional de atenção de saúde”. In: Estado federativo e políticas sociais: determinantes da descentralização. Rio de Janeiro: Renavam; São Paulo: Fapesp.

2001. "Federalismo e Relações Intergovernamentais no Brasil: A Reforma dos Programas Sociais". Dados - Revista de Ciências Sociais, Rio de Janeiro: vol. 45, n ${ }^{\circ} 3$, pp. 431-457.

. 2003. "Financiamento federal e gestão local de políticas sociais: o difícil equilíbrio entre regulação, responsabilidade e autonomia". Ciência e Saúde Coletiva. Rio de Janeiro: vol. 8, nº 2. Disponível em: http:/ / www.scielo.br/scielo.php?script=sci_arttext\&pid=S141381232003000200002\&lng=pt\&nrm=iso. Acesso em: 4 set. 2006.

2004. "Federalismo e Políticas Sociais no Brasil: problemas de coordenação e autonomia”. Revista São Paulo em Perspectiva, São Paulo: vol. $18, \mathrm{n}^{\circ}$ 2, pp. 17-26.

216 2005. "A política da política de saúde no Brasil". In: LIMA, N. T. et al. (orgs.). Saúde e democracia: história e perspectivas do SUS. Rio de Janeiro: Fiocruz.

.; MARQUES, E. 2002. "Municipalização da saúde no Brasil: diferenças regionais, poder do voto e estratégias de governo". Ciência e Saúde Coletiva. Rio de Janeiro: vol. 7, $\mathrm{n}^{\circ}$ 3. Disponível em: http:/ /www.scielo.br/scielo.php?script=sci_arttext\&pid=S1413-81232002000300006\&lng=pt\&nrm=iso . Acesso em: 4 set. 2006.

.; RODRIGUES, V. (orgs.). 1998. Descentralização das políticas sociais no estado de São Paulo. São Paulo/Brasília: Fundap e Fapesp/Ipea.

BAHIA, L. 2005. "O SUS e os desafios da universalização do direito à saúde: tensões e padrões de convivência entre o público e o privado no sistema de saúde brasileiro" In: LIMA, N. T. et al. (orgs.). Saúde e democracia: história e perspectivas do SUS. Rio de Janeiro: Fiocruz.

BARROS, E. 2003. "Financiamento do sistema de saúde no Brasil: marco legal e comportamento do gasto". In: Projeto de Desenvolvimento de Sistemas e Serviços de Saúde $n^{\circ} 4$. Brasília: Organização Pan-americana da Saúde, Secretaria da Atenção à Saúde e Ministério da Saúde.

.; PORTO, S. 2002. Health care in Brazil: equity as challenge. Paper prepared for Global Development Network. 
.; PIOLA, S. F.; VIANNA, S. M. 1996. "Desafios na gestão”, "Implementando a reforma sanitária" e "Processo de descentralização". In: Política de Saúde no Brasil: diagnóstico e perspectivas. Brasília: IPEA.

BNDES - Banco Nacional de Desenvolvimento Econômico e Social. 2001. Informe-se: Receita municipal: a importância das transferências do FPM e do SUS, n ${ }^{\circ} 28$, junho.

BODSTEIN, R. C. de A.; FONSECA, C. M. O. 1989. "Desafio da Reforma Sanitária: consolidação de uma estrutura permanente de serviços básicos de saúde”. In: COSTA, N. do R. et al. Demandas populares, políticas públicas e saúde. Rio de Janeiro: Vozes e Abrasco.

BRASIL. 1988. Constituição da República Federativa do Brasil de 1988. In: www.planalto.gov.br. Acesso em: 30 de agosto de 2006.

CARVALHO, J. M. de 2007. Cidadania no Brasil - O longo caminho. Rio de Janeiro: Civilização Brasileira.

CNS - Conselho Nacional de Saúde. 2007. "Resoluções de 1992 e 2007".

Disponível em: http:/ / conselho.saude.gov.br/resolucoes . Acesso em: 8 de outubro de 2007.

COHN, A. 1989. "Caminhos da reforma sanitária”. Lua Nova, $\mathrm{n}^{\circ}$ 19, pp. 123-140.

. 1992. "Descentralização, cidadania e saúde". São Paulo em Perspectiva, $\mathrm{n}^{\circ} 6(4)$, pp. 70-76, out.-dez. $5-23$.

1994. "Descentralização, saúde e cidadania”. Lua Nova, nº 32, pp.

. 2003. "A saúde na previdência social e na Seguridade Social: antigos estigmas e novos desafios". In: COHN, A.; ELIAS, P. Saúde no Brasil: políticas e organização de serviços. $5^{\text {a }}$ ed. São Paulo: Cortez.

2005. "O SUS e o direito à saúde: universalização e focalização nas políticas de saúde”. In: LIMA, N. T. et al. (orgs.). Saúde e democracia: história e perspectivas do SUS. Rio de Janeiro: Fiocruz.

.; ELIAS, P. 2003. Saúde no Brasil: políticas e organização de serviços. $5^{\mathrm{a}}$ ed. São Paulo: Cortez.

; ELIAS, P. E. M. (orgs.). 2005. Descentralização e saúde no estado de São Paulo. As articulações entre as esferas do governo. São Paulo: Cedec.

CONFERÊNCIAS NACIONAIS DE SAÚDE. 2007. "Relatórios do Conselho Nacional de Saúde”. Disponível em: http://conselho.saude.gov. br/biblioteca/Relatorios.htm. Acesso em: 8 out. 2007.

CORDEIRO, H. 1991. Sistema Único de Saúde. Rio de Janeiro: Ayuri Editorial.

. 2001. "Descentralização, universalidade e equidade nas reformas da saúde”. Ciência e Saúde Coletiva. Rio de Janeiro, vol. 6, nº 2. Disponí- 
vel em: http:/ / www.scielo.br/scielo.php?script=sci_arttext\&pid=S141381232001000200004\&lng=pt\&nrm=iso . Acesso em: 5 jan. 2007.

2004. O Instituto de Medicina Social e a luta pela reforma sanitária: contribuição à história do SUS’. Physis, jul./dez. 2004, vol. 14, $\mathrm{n}^{\circ} 2$, pp. 343-362.

COSTA, N. do R. et al. 1989. Demandas Populares, Políticas Públicas e Saúde. Rio de Janeiro: Vozes e Abrasco.

. 2001. "A descentralização do sistema público de saúde no Brasil: balanço e perspectivas”. In: NEGRI, B.; GIOVANNI, G. Di (orgs.). Brasil: radiografia da saúde. Campinas, SP: Unicamp.

DAB - Departamento de Atenção Básica. 2007. "Atenção básica e a saúde da família”. Disponível em: http://dtr2004.saude.gov.br/dab/abnumeros.php\#historico. Acesso em: 27 set. 2007.

. 2008. "Atenção básica e a saúde da família". In: http:/ / dtr2004.saude.gov.br/dab/atencaobasica.php. Acesso em: 12 fev. 2008.

DAGNINO, E. (org.). 2002. Sociedade civil e espaços públicos no Brasil. São Paulo: Paz e Terra.

ESCOREL, S. 1998. Reviravolta na saúde: origem e articulação do movimento sanitário. Rio de Janeiro: Fiocruz.

.; NASCIMENTO, D. R. do; EDLER, F. C. 2005. "As origens da reforma sanitária”. In: LIMA, N. T. et al. (orgs.). Saúde e democracia: história e perspectivas do SUS. Rio de Janeiro: Fiocruz.

FAVARET, A. C. de S. C. 2003. "A vinculação constitucional de recursos para a saúde: avanços, entreves e perspectivas”. Ciência Ẽ Saúde Coletiva, $\mathrm{n}^{\circ} 8(2)$, pp. 371-378.

FBH - Federação Brasileira de Hospitais. 2008. "Institucional”. Disponível em: http://www.fbh.com.br/index.php?a=inst_inst.php . Acesso em: 9 jan. 2008.

FLEURY, S. 1991. "Avaliação Comparativa das Ações Integradas de Saúde". Saúde em Debate, $\mathrm{n}^{\circ}$ 3. fevereiro.

GALLO, E. 1988. "Da reforma ao reformismo: o Cebes e o 'movimento sanitário', da ditadura à 'nova república'”. Saúde em Debate, outubro.

GOULART, F. A. de A. 1996. Municipalização: veredas. Caminhos do movimento municipalista de saúde no Brasil. Rio de Janeiro: Abrasco/Canasems.

GOUVEIA, R.; PALMA, J. J. 1999. "SUS: na contramão do neoliberalismo e da exclusão social”. Estudos Avançados, São Paulo, vol. 13, nº 35 Disponível em: http:/ / www.scielo.br/scielo.php?script=sci_arttext\&pid=S010340141999000100014\&lng=en\&nrm=iso. Acesso em: 25 out. 2006.

GUIMARÃES, R.; TAVARES, R. A. W. 1994. Saúde e sociedade no Brasil: anos 80. Rio de Janeiro: Relume-Dumará. 
HOUTZAGER, P. 2004. "Além da sociedade civil e do Estado: autoridade política, instituições e mobilização popular”. In: HOUTZAGER, P. Os últimos cidadãos: conflito e modernização no Brasil rural 1964-1995. São Paulo: Globo.

IBGE - Instituto Brasileiro de Geografia e Estatística. 2002. Estatísticas da saúde: assistência médico-sanitária 2002. Disponível em: http://www. ibge.gov.br/home/estatistica/populacao/condicaodevida/ams / default.shtm . Acesso em: 15 jan. 2007.

LEVCOVITZ, E.; LIMA, L. D. de; MACHADO, C. V. 2001. "Política de saúde nos anos 90: relações intergovernamentais e o papel das Normas Operacionais Básicas”. Ciência e Saúde Coletiva. Rio de Janeiro: vol. 6, $\mathrm{n}^{\circ}$ 2. Disponível em: http://www.scielo.br/scielo.php?script=sci_ arttext\&pid=S1413-81232001000200002\&lng=pt\&nrm=iso . Acesso em: 28 set. 2006.

LIMA, N. T. et al. (orgs.). 2005. Saúde e democracia: história e perspectivas do SUS. Rio de Janeiro: Fiocruz.

.; FONSECA, C. M. O.; HOCHMAN, G. 2005. "A saúde na construção do Estado Nacional no Brasil: reforma sanitária em perspectiva histórica”. In: LIMA, N. T. et al. (orgs.). Saúde e democracia: história e perspectivas do SUS. Rio de Janeiro: Fiocruz.

MARQUES, R. M. 1998. "Descentralização da política de saúde" In: ARRETCHE, M.; RODRIGUES, V. (orgs.). Descentralização das políticas sociais no estado de São Paulo. São Paulo/Brasília: Fundap e Fapesp/ Ipea.

NEGRI, B.; GIOVANNI, G. Di (orgs.). 2001. Brasil: radiografia da saúde. Campinas, SP: Unicamp.

NEMES FILHO, A. 1992. Os médicos sanitaristas e a política de saúde no Estado de São Paulo no período de 1976 a 1988. Departamento de Prática de Saúde Pública, Universidade de São Paulo. Faculdade de Saúde Pública, dissertação de mestrado.

NOB - Norma Operacional Básica do Sistema Único de Saúde/NOB-SUS 96. 1996. Brasília: Ministério da Saúde.

NORONHA, J. C.; LEVCOVITZ, E. 1994. "AIS-SUDS-SUS: os caminhos do direito à saúde”. In: GUIMARÃES, R.; TAVARES, R. A. W. Saúde e sociedade no Brasil: anos 80. Rio de Janeiro: Relume-Dumará.

OPAS - Organização Panamericana da Saúde. 2005. Brasil: o perfil do sistema de serviços de saúde. Brasília (mimeo).

PAIM, J. S. 1986. "Ações intergradas de saúde (AIS): por que não dois passos atrás?”. Cadernos de Saúde Pública, Rio de Janeiro, nº 2(2) abril/ junho. 
PIMENTA, A. L. 1993. "O SUS e a municipalização à luz da experiência concreta”. Saúde Ẽ sociedade. São Paulo, n 2(1), pp. 25-40.

PIOLA, S. F.; BIASOTO JR., G. 1980. "Financiamento do SUS nos anos 90”. In: POSSAS, C. de A. Saúde, medicina e trabalho no Brasil: uma antropofagia do capitalismo selvagem. Departamento de Antropologia Social, Instituto de Filosofia e Ciências Humanas, Universidade Estadual de Campinas, dissertação de mestrado.

RODRIGUES NETO, E. 1997. "A via do parlamento” In: FLEURY, S. (org.). Saúde e democracia: a luta do Cebes. São Paulo: Lemos Editorial.

SADDI, F. 2004. Estado, sociedade e descentralização da política pública de saúde no México 1982-2000 e no Brasil 1985-1998: construindo um novo dominio público em contextos de dupla transição. Departamento de Sociologia, Faculdade de Filosofia, Letras e Ciências Humanas da Universidade de São Paulo: tese de doutoramento.

TATAGIBA, L. 2002. "Os conselhos gestores e democratização das políticas públicas no Brasil”. In: DAGNINO, E. (org.). Sociedade civil e espaços públicos no Brasil. São Paulo: Paz e Terra.

TEIXEIRA, S. M. F. 1987. "O dilema reformista na reforma sanitária brasileira”. Revista Administração pública, Rio de Janeiro, no 21(4), outubro/dezembro.

220 UGÁ, M. A. D.; MARQUES, R. M. 2005. “O financiamento do SUS: trajetória, contexto e constrangimentos”. In: LIMA, N. T. et al. (orgs.). Saúde e democracia: história e perspectivas do SUS. Rio de Janeiro: Fiocruz.

D.; SANTOS, I. S. 2006. "Uma análise da progressividade do financiamento do Sistema Único de Saúde (SUS)". Caderno de Saúde Pública. Rio de Janeiro, vol. 22, $\mathrm{n}^{\circ}$ 8. Disponível em: http:// www.scielo.br/scielo.php?script=sci_arttext\&pid=S0102-311X2006000800008\&lng=pt\&nrm=iso. Acesso em: 2 fev. 2007.

VIANA, A. L. d'Á. et al. 2002. "Mudanças significativas no processo de descentralização do sistema de saúde no Brasil”. Cadernos de Saúde Pública, Rio de Janeiro, vol. 18. In: http://www.scielo.br/scielo.php?script=sci_ arttext\&pid=S0102-311X2002000700014\&lng=pt\&nrm=iso. Acesso em: 28 set. 2006.

VIANNA, S. M. 1992. "A descentralização tutelada”. Saúde em Debate. Rio de Janeiro, $\mathrm{n}^{\circ} 35$, julho. 
ANEXO

\section{Quadro de siglas}

\begin{tabular}{|c|c|}
\hline ABH & Associação Brasileira de Hospitais \\
\hline ABRASCO & Associação Brasileira de Pós-Graduação em Saúde Coletiva \\
\hline ABRAMGE & Associação Brasileira de Medicina de Grupo \\
\hline AIS & Ações Integradas de Saúde \\
\hline AMB & Associação Médica Brasileira \\
\hline Cebes & Centro Brasileiro de Estudos da Saúde \\
\hline CIB & Comissão Intergestores Bipartites \\
\hline CIT & Comissão Intergestores Tripartite \\
\hline CIS & Comissões Interinstitucionais de Saúde \\
\hline CONASP & Conselho Nacional de Administração da Saúde Previdenciária \\
\hline CONASEMS & Conselho Nacional de Secretários Municipais de Saúde \\
\hline CONASS & Conselho Nacional de Secretários Estaduais de Saúde \\
\hline CPMF & Contribuição Provisória sobre a Movimentação Financeira \\
\hline FBH & Federação Brasileira de Hospitais \\
\hline FENAESS & Federação Nacional de Estabelecimentos e Serviços de Saúde \\
\hline IAP & Instituto de Aposentadoria e Pensão \\
\hline Inamps & Instituto Nacional de Assistência Médica e Previdência Social \\
\hline INPS & Instituto Nacional de Previdência Social \\
\hline LOS & Lei Orgânica da Saúde \\
\hline MPAS & Ministério de Previdência e Assistência Social \\
\hline NOB & Norma Operacional Básica \\
\hline PAB & Piso de Atenção Básica \\
\hline PACS & Programa de Agentes Comunitários de Saúde \\
\hline PAS & Plano de Assistência à Saúde \\
\hline PEC & Projeto de Emenda Constitucional \\
\hline Piass & Programa de Interiorização de Ações de Saúde e Saneamento \\
\hline
\end{tabular}




\begin{tabular}{|l|l|}
\hline PLUS & Plano de Localização de Unidade de Serviços \\
\hline PMC & $\begin{array}{l}\text { Sistema Integrado de Prestação de Serviços de Saúde no Norte de } \\
\text { Minas Gerais(Projeto Montes Claros) }\end{array}$ \\
\hline Prev-Saúde & Programa Nacional de Serviços Básicos de Saúde \\
\hline PSF & Programa Saúde da Família \\
\hline QUALIS/PSF & Qualidade Integrada de Saúde no Programa da Saúde da Família \\
\hline SAMHPS & Sistema de Assistência Médico-Hospitalar da Previdência Social \\
\hline SES & Secretaria Estadual de Saúde \\
\hline SMS & Secretaria Municipal de Saúde \\
\hline SUDS & Sistema Unificado e Descentralizado de Saúde \\
\hline SUS & Sistema Único de Saúde \\
\hline UERJ & $\begin{array}{l}\text { Instituto da Medicina Social da Universidade Estadual do Rio de } \\
\text { Janeiro }\end{array}$ \\
\hline
\end{tabular}




\section{DA INFLEXÃO PRÉ-CONS}

MUNICIPALIZADO

\section{MONIKA DOWBOR}

Este artigo adota a análise das reformas do setor de saúde pelo prisma da atuação de atores capazes de incidir na política. Esse recorte permitiu, em primeiro lugar, identificar a inflexão préconstitucional na primeira década de 1980, possibilitada pelo aproveitamento de oportunidades institucionais pelos profissionais reformistas de saúde, e anterior à Constituição de 1988, considerada como divisor de águas na literatura preocupada com o setor público de saúde. O segundo argumento referese ao processo da implementação do Sistema Único de Saúde (SUS) e focaliza a mudança de atores com capacidade de levar as reformas adiante. Os termos e resultados da implementação do sistema via municipalização de atenção básica com maciça adoção de programas federais aparece como fruto de negociação entre dois dos atores institucionalizados - o Ministério de Saúde e os secretários municipais de saúde.

Palavras-chave: Política pública; Reformas; Movimento social; Saúde. 